\title{
ANALISIS IKLAN RUMAH SPA DAN SALON KECANTIKAN DI KECAMATAN UBUD
}

\author{
Indra Brata \\ Universitas Warmadewa \\ adibrata@gmail.com
}

\begin{abstract}
Abstrak
Judul penelitian ini adalah analisis iklan rumah spa dan salon kecantikan di kecamatan Ubud. Penelitian ini membahas tentang struktur wacana, unsur verbal dan unsur nonverbal yang terdapat pada iklan yang digunakan oleh rumah spa sebagai media promosi. Penelitian ini menggunakan teori wacana oleh Van Dijk (2009) dan teori semiotik oleh Pierce (2007). Sumber data pada penelitian ini adalah iklan yang dipajang dipinggir jalan yang berada di kecamatan Ubud. Dalam pengumpulan data, penulis menggunakan metode penelitian lapangan dengan menggunakan teknik dokumentasi dan pencatatan. Data yang telah terkumpul kemudian dianalisa menggunakan metode hermeutika dan teknik analisis data kualitatif berdasarkan ruang lingkup permasalahannya. Berdasarkan hasil analisis yang dilakukan, terdapat tiga temuan dalam analisis ini yaitu, (1) Enam iklan rumah spa tersebut memiliki strukur makro yang lengkap, sedangkan pada tatanan superstrukur, ada beberapa iklan yang memiliki superstruktur iklan kurang lengkap, pada tatanan struktur mikro setiap iklan memiliki unsur semantik dan sintaksis, namun ada beberapa iklan yang memiliki unsur retoris seperti. (2) Enam iklan yang dianalisis pada penelitian ini memiliki makna verbal yang dianalisis melalui strukur makro dan mikro yang merupakan bagian struktur wacana pada iklan. (3) Enam iklan yang dianalisis pada penelitian ini memiliki makna nonverbal yang diungkapkan melalui tanda yang terdapat pada iklan tersebut berupa ikon, indeks dan simbol.
\end{abstract}

Kata kunci: wacana dan teks, iklan, semiotik, verbal, nonverbal

\begin{abstract}
The title of this research is the analysis of home spa and beauty salon advertisment in the district of Ubud. This research discusses about the structure of the discourse, the meaning of verbal and nonverbal meaning found in the advertisment used by home spa as a media promotion. This research uses the theory of discourse by Van Dijk (2009) and semiotic theory by Pierce (2007). Data source in this research is the advertisement displayed alongside at the street which located in Ubud district. In collecting the data, the writter use field research method with the documentation and record technique. Then the data analyzed by hermeutika methods and qualitative data analysis techniques based on the scope of the problem. Based on the result analysis, there are three findings there are: (1) Six advertisment spa house has the structure of a macro that is complete, in superstructure, there are some advertising that have a superstructure advertisment are incomplete, and in micro structure of each ad has a semantic and syntactic elements, but there are some advertisment that have an element of rhetorical. (2) Six advertise were analyzed in this study had a verbal meanings are analyzed through on macro and micro structure of which is part of the structure of discourse in the advertisement. (3) Six advertisment were analyzed in this study had a nonverbal meanings expressed through the sign contained in the advertise as icons, indices and symbols.
\end{abstract}

Keywords: discourse and text, advertising, semiotic, verbal, nonverbal

\section{PENDAHULUAN}

Periklanan merupakan salah satu alat yang paling umum digunakan oleh sebuah perusahaan untuk mengarahkan komunikasi persuasif pada pembeli sasaran dan masyarakat. Iklan menurut kamus besar Ba- hasa Indonesia adalah berita pesanan untuk mendorong, membujuk khalayak ramai agar tertarik pada barang dan jasa yang ditawarkan. Periklanan terfokus pada media massa seperti surat kabar, televisi, radio dan papan iklan. Periklanan menawarkan keunggulan 
signifikan diatas teknik promosi lainnya.

Tujuan dimunculkannya iklan adalah untuk memperkenalkan dan mempengaruhi publik agar mau membeli atau menggunakan barang dan jasa yang ditawarkan oleh sebuah perusahaan. Maka dari itu tampilan iklan yang terdapat pada media, baik media elektronik maupun media cetak dibuat dengan bentuk dan tampilan yang beragam dengan bahasa yang kreatif dan menarik. Bahasa yang digunakan dalam iklan bersifat persuasif, selalu berusaha menggugah emosi pembaca atau pendengar. Tujuannya agar yang menjadi sasaran iklan (konsumen) melakukan sesuatu atau bertindak sesuai dengan amanat iklan tersebut. Oleh karena itu, dalam bahasa iklan, katakata yang digunakan dalam bentuk rayuan, anjuran atau ajakan yang dapat menimbulkan rasa penasaran.

Iklan dibagi menjadi dua jenis, yaitu iklan komersil dan iklan layanan masyarakat. Iklan komersil adalah iklan yang ditata secara khusus untuk keperluan memperkenalkan barang, jasa, pelayanan untuk konsumen melalui media periklanan. Tujuan iklan komersil adalah untuk mendapatkan keuntungan-keuntungan ekonomi. Kategori yang kedua adalah iklan layanan masyarakat, yaitu iklan yang bersifat non-profit. Kesulitan konsumen untuk memahami secara kontekstual slogan-slogan yang digunakan di dalam iklan sedikit banyak disebabkan karena orang sulit memahami bahasa dan struktur iklan. Dan oleh karena itu penting untuk mengemukakan hakikat bahasa, struktur pembuatan iklan serta membuat analisis wacana kontekstual terhadap iklan-iklan yang diiklankan. Wacana sebagai ilmu bahasa juga memiliki unsurunsur yang yang terkait dalam kajiannya, unsur-unsur tersebut di antaranya, yang pertama adalah teks. Teks adalah bahasa yang berfungsi menyampaikan pesan atau informasi dalam konteks situasi, berlainan dengan kata-kata atau kalimat-kalimat lepas yang mungkin dituliskan. Berdasarkan paparan pada latar belakang di atas, penelitian ini berusaha menganalis struktur dan makna yang terdapat pada iklan komersial, baik pada unsur verbal maupun nonverbal yang akan dianalisis pada iklan salon spa dan salon kecantikan. Selain itu analisis periklanan telah menjadi studi yang sangat popular, sehingga memunculkan berbagai jenis penelitian yang mengkaji tentang analisis struktur dan makna iklan.

Kajian mengenai iklan antara lain dilakukan oleh Mulyawan (2005) dalam tesisnya yang berjudul "Wacana Iklan Komersial Media Cetak: Kajian Hipersemiotika" menganalisis sejumlah iklan komersial media cetak dalam empat rumusan masalah. Adapun keempat masalah tersebut menganalis tentang struktur iklan, struktur grammatikal dan leksikal, makna dan pesan yang ingin disampaikan, serta ideologi yang melatarbelakanginya. Teori utama yang digunakan dalam penelitian Mulyawan (2005) adalah teori struktur wacana oleh van Dijk (dalam Sobur 2001) dan teori Hipersemiotika oleh Piliang (2003). 
Mahayani (2011) pada penelitiannya yang berjudul “ Teks iklan layanan masyarakat: Kajian semiotik " dan dimuat dalam kumpulan tesis program pascasarjana universitas Udayana yang mengkaji sejumlah iklan layanan masyarakat. Dalam menganalisis permasalahannya Sri Mahayani menggunakan model analisis wacana van Dijk (1997) dengan rumusan masalah sebagai berikut: (1) analisis pada struktur mikro pada teks verbal, (2) makna yang terdapat pada tanda verbal dan nonverbal pada semiologis tingkat satu ataupun tingkat dua pada IKLM, (3) ideologi yang melatarbelakangi IKLM tersebut. Adapun Teori utama yang digunakan adalah teori semiotik oleh Barthes (1977) dan didukung oleh teori lainnya seperti teori tindak tutur oleh Austin (1962) dan Searle (1969). Dari segi objek penelitian, Mahayani (2011) menggunakan iklan layanan masyarakat (IKLM) sebagai objek penelitian, sedangkan penelitian ini menggunakan iklan komersil sebagai objek penelitian. Selain itu Penelitian Mahayani (2011) menganalisis iklan terkait dengan makna konotasi dan denotasi yang diaplikasikan dengan mengunakan teori semiotik Roland Barthes (1977) sedangkan penelitian ini menganalisis makna verbal pada iklan dan makna nonverbal yang berupa ikon, indeks, dan simbol dengan menggunakan teori semiotik oleh Pierce (2007) dalam penelitian ini.

Data dalam penelitian ini berupa iklan komersil, khususnya iklan rumah spa dan salon kecantikan yang berupa spanduk, bill- board dan brosur. Data dijaring menggunakan metode field research (penelitian lapangan) dan observasi. Hal ini berarti data dicari langsung sesuai dengan kondisi yang ada di lapangan. Dari beberapa rumah spa dan salon kecantikan yang ada, penulis mengamati beberapa iklan dan kemudian dipilih untuk dijadikan data dalam penelitian ini. Teknik pengumpulan data yang digunakan dalam penelitian ini adalah teknik dokumentasi dan teknik catat. Setiap iklan spa didokumentasikan menggunakan kamera dan dikumpulkan hingga menghasilkan 17 data iklan spa. Dari 17 data yang diperoleh nantinya akan dipilih sesuai keperluan yang diperlukan untuk data analisis. Setelah data dipilah kemudian dianalisis ke sesuai rumusan masalah. Berikut teknik analisis yang diterapkan pada penelitian ini: (1) Iklan dipilah ke dalam bentuk verbal dan nonverbal. (2) Bentuk verbal dianalis sesuai struktur wacana, kemudian di bagi atas struktur makro dan mikro yang dianalisis berdasarkan teori wacana Van Dijk (2009) dan dilanjutkan dengan menganalisis makna dari unsur verbal yang terdapat pada iklan tersebut. (3) Analisis dilanjutkan menganalisis unsur nonverbal dalam tanda yang berupa ikon, indeks, dan simbol dalam bentuk nonverbal pada iklan yang menggunakan teori semiotik oleh Pierce (2007). Hasil analisis data pada penelitian ini disajikan dengan menggunakan metode formal dan informal. 


\section{KONSEP DAN KERANGKA TEORI}

Konsep

\section{Konsep Wacana dan Teks}

Halliday and Hasan dalam buku Cohesion in English (1976) menyatakan bahwa wacana dan teks merupakan dua istilah yang sama dan saling berkaitan. Halliday and Hasan berpendapat Teks merupakan rangkaian kalimat yang saling berkaitan, bukan hanya sebagai unit gramatikal, melainkan merupakan satu unit makna. Wacana merupakan kalimat-kalimat yang secara operasional berkedudukan sebagai satu kesatuan.

\section{Konsep iklan}

iklan menurut Kotler dan Amstrong (1991:567): “Any paidform of non personal presentation and promotion of ideas, goods or service by an identified sponsor" Periklanan merupakan salah satu bentuk penyajian dan promosi mengenai ide, barang/ jasa yang bersifat non personal yang diselenggarakan melalui media yang dibayar oleh sponsor yang dikenal. Kotler, dalam karya sebelumnya, juga telah mengidentifikasi iklan yang menggunakan media massa. Periklanan menggunakan media massa dianggap menjadi dimensi penting dalam periklanan, meskipun menimbulkan pertanyaan tentang apa yang disebut dengan media massa untuk saat ini. Dia menyarankan 'pembawa pesan', yang didalamnya termasuk TV, Radio, bioskop, pers, poster, dan Internet.

\section{Konsep Struktur Iklan}

Menurut Leech (1966) secara umum setiap iklan, khususnya iklan media cetak, terdiri atas struktur bagian sebagai berikut: pertama adalah Headline yang merupakan kepala sebuah iklan yang berfungsi sebagai hal yang ingin diperlihatkan kepada konsumen atau pembaca. Kedua adalah Illustration yang merupakan latar belakang sebuah iklan yang memberikan gambaran terhadap iklan tersebut. Ketiga adalah Body copy yang merupakan isi dari sebuah iklan yang berisikan informasi dan pesan yang terdapat pada iklan tersebut. Empat, Signature line (logo) merupakan tampilan produk yang diiklankan berikut harga, slogan, atau merek. Dan yang terakhir adalah Standing details merupakan penutup sebuah iklan yang terdapat pada bagian bawah/akhir iklan. Pada bagian ini biasanya berisikan informasi tambahan yang berkaitan dengan produk yang diiklankan, seperti alamat perusahaan, pusat informasi, dan lain-lain.

\section{Konsep Unsur Verbal dan Nonverbal}

Philips menyatakan bahwa tanda verbal dijelaskan dengan menggunakan tata bahasa yang benar dan kata-kata yang tepat, volume, kejelasan ucapan, dan fleksibilitas, suara-suara kualitas yang menambah komunikasi verbal yang baik. (Philips, 1983: 38). Selain itu Philips juga menyatakan tentang unsur nonverbal di dalam bukunya tersebut, yang dinyatakan bahwa unsur nonverbal mengacu pada semua aspek lain dari proses komunikasi. Tanda nonverbal meliputi pos- 
tur, nada suara, gerak tubuh, dan ekspresi wajah (Philips, 1983: 12).

\section{Kerangka Teori}

\section{Teori Wacana}

Menurut van Dijk, penelitian atas wacana tidak cukup hanya didasarkan pada analisis teks semata, karena teks hanya hasil dari suatu praktik produksi yang harus juga diamati. Melalui karyanya Van Dijk (2009) membentuk suatu kerangka analisis wacana yang dapat didayagunakan. Beliau melihat suatu wacana terdiri dari berbagai struktur / tingkatan yang masing-masing bagian saling mendukung. Van Dijk membaginya kedalam tiga tingkatan sebagai berikut:

1) Struktur Makro: ini merupakan makna global atau umum dari suatu teks yang dapat dipahami dengan melihat topik dari suatu teks. Tema wacana ini bukan hanya isi, tetapi juga sisi tertentu dari suatu peristiwa.

2) Superstruktur: merupakan kerangka suatu teks: bagaimana struktur dan elemen wacana itu disusun dalam teks secara utuh.

3) Struktur mikro: adalah makna wacana yang dapat diamati dengan menganalisis kata, kalimat, proposisi, anak kalimat, parafrase, yang digunakan dan sebagainya.

Struktur atau elemen wacana yang dikemukakan oleh Van Dijk (2009) ini dapat digambarkan sebagai berikut:

Tabel 1 Element Wacana Van Djik

\begin{tabular}{|c|c|c|}
\hline $\begin{array}{l}\text { Struktur } \\
\text { Wacana } \\
\end{array}$ & Hal yang Diamati & Elemen \\
\hline Struktur Makro & $\begin{array}{c}\text { TEMATIK } \\
\text { (Apa yang dikatakan?) }\end{array}$ & Topik \\
\hline Superstruktur & $\begin{array}{c}\text { SKEMATIK } \\
\text { (Bagaimana pendapat disusun dan dirangkai?) }\end{array}$ & Skema \\
\hline Struktur Mikro & $\begin{array}{c}\text { SEMANTIK } \\
\text { (Makna yang ingin ditekankan dalam teks }\end{array}$ & $\begin{array}{c}\text { Latar, detail, maksud, } \\
\text { peranggapan, nominalisasi }\end{array}$ \\
\hline Struktur Mikro & $\begin{array}{c}\text { SINTAKSIS } \\
\text { (Bagaimana pendapat disampaikan?) }\end{array}$ & $\begin{array}{c}\text { Bentuk kalimat, koherensi, } \\
\text { kata ganti }\end{array}$ \\
\hline Struktur Mikro & $\begin{array}{c}\text { STILISIK } \\
\text { (Pilihan kata apa yang digunakan?) }\end{array}$ & Leksikon \\
\hline Struktur Mikro & $\begin{array}{c}\text { RETORIS } \\
\text { (Bagaimana dan dengan cara apa penekanan } \\
\text { dilakukan?) }\end{array}$ & Grafis, metafora, Ekspresi \\
\hline
\end{tabular}

\section{Teori Semiotik}

Bagi Pierce (2007) tanda adalah "sign is something which stands to somebody for something in some respect or capacity" yang berarti tanda adalah sesuatu bagi seseorang dalam beberapa hal atau kapasitas. Pierce menyatakan bahwa ada suatu hal yang digunakan agar tanda bisa berfungsi, oleh Pierce itu disebut ground. Konsekuensinya tanda harus selalu terdapat dalam 
hubungan triadik yang meliputi ground, object, dan interpretant. Berikut merupakan skema teori tanda "Peircean":

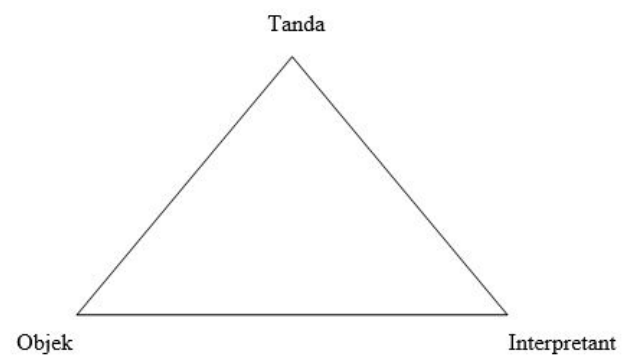

Diagram 1 skema teori tanda "Peircean" Sumber: Danesi (2011: 33)

Tiga dimensi yang sudah dijelaskan diatas yang berupa tanda, objek dan interpretant selalu hadir dalam signifikasi. Peirce mengemukakan teori segitiga makna yang terdiri dari tiga elemen utama, yakni tanda (ground), object, dan interpretant. Tanda adalah sesuatu yang berbentuk fisik yang dapat ditangkap oleh panca indera manusia dan merupakan sesuatu yang merujuk (merepresentasikan) hal lain di luar tanda itu sendiri. Objek menurut Peirce terdiri dari Simbol (tanda yang muncul dari kesepakatan), Ikon (tanda yang muncul dari perwakilan fisik) dan Indeks (tanda yang muncul dari hubungan sebab-akibat). Dan yang terakhir interpretant adalah makna yang dikandung dari tanda itu sendiri. Jadi ketiga dimensi tersebut yang berupa tanda, objek, dan interpretant saling berhubungan dan terikat satu sama lain.

\section{PEMBAHASAN}

Pada tahapan analisis struktur wacana pada iklan rumah spa, makna pada unsur verbal dan makna vada tanda nonverbal ini, dari setiap iklan yang dipilih berdasarkan jenis iklan, dianalisis menggunakan teori wacana Van Dijk (2009) dan teori semiotik Pierce (2007). Menurut Van Dijk, terdapat 3 struktur yang menjadi pembentuk pada wacana iklan, ketiga unsur tersebut adalah struktur makro, supersutruktur dan struktur mikro, sedangkan pada analisis unsur nonverbal menurut Pierce (2007) terdapat pada tanda yaitu ikon, indeks dan simbol. Berikut analisis dari beberapa contoh iklan yang dijelaskan secara rinci pada tabel 02 hingga tabel 13:

Iklan Daisy Spa (D1) merupakan iklan rumah spa yang diterbitkan oleh perusahaan Daisy Spa. Rumah spa ini terletak di jalan raya monkey forest, kecamatan Ubud. Iklan ini bertujuan untuk menawarkan jasa spa dan memberitakan jenis jasa yang akan dilayani dirumah spa tersebut, selain itu iklan ini diterbitkan untuk menarik minat para pelanggan agar mengetahui informasi harga yang harus dibayarkan untuk setiap jenis layanan spa yang dipilih. Berikut tampilan hasil analisis pada iklan Daisy Spa dengan metode formal dalam bentuk diagram dan tabel untuk menunjang hasil analisis agar menjadi lebih detail:

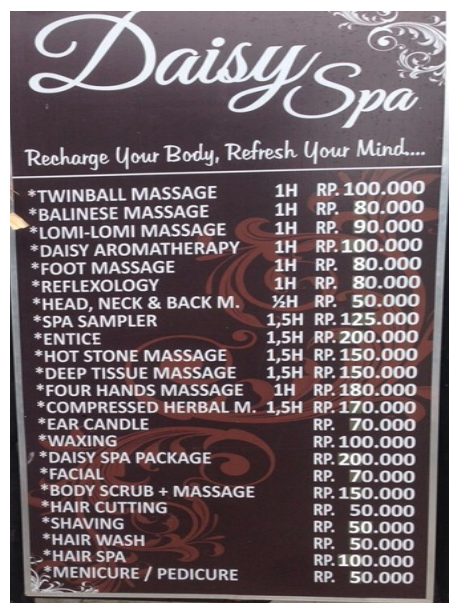


Tabel 02: Struktur wacana iklan D1

\begin{tabular}{|c|c|c|c|c|c|c|c|c|c|}
\hline \multicolumn{2}{|c|}{ Struktur Makro } & \multicolumn{6}{|c|}{ Superstruktur } & \multicolumn{2}{|c|}{ Struktur Mikro } \\
\hline Tematik & $\tilde{\mathrm{O}}$ & Skematik & $\mathrm{H}$ & I & $\mathrm{BC}$ & SL & $\mathrm{SD}$ & Semantik & $\ddot{O}$ \\
\hline & & & $\ddot{O}$ & & $\ddot{O}$ & $\ddot{\mathrm{O}}$ & & Sintaksis & $\ddot{\mathrm{O}}$ \\
\hline & & & & & & & & Stilisik & \\
\hline & & & & & & & & Retoris & \\
\hline
\end{tabular}

Keterangan : $\mathrm{H}=$ Headline

$$
\begin{aligned}
& \mathrm{I}=\text { Illustration } \\
& \mathrm{BC}=\text { Bodycopy } \\
& \mathrm{SL}=\text { Signature Line } \\
& \mathrm{SD}=\text { Standing Detail }
\end{aligned}
$$

Deskripsi Tanda pada unsur nonverbal:

Tabel 03: Tanda iklan D1

\begin{tabular}{|c|c|}
\hline Ikon & $\ddot{O}$ \\
\hline Indeks & \\
\hline Simbol & \\
\hline
\end{tabular}

Data iklan yang kedua (D2) adalah iklan juga terdapat beberapa unsur verbal dan yang diterbitkan oleh perusahaan Bi Sama nonverbal yang bisa dianalisis. Berikut Spa. Rumah spa ini berlokasi di kawasan tampilan hasil analisis pada Bi Sama Spa wisata Monkey forest Ubud. Tampilan pada dengan metode formal dalam bentuk diaiklan ini menampilkan jenis layanan yang gram dan tabel untuk menunjang hasil anabisa dinikmati ditempat spa tersebut dan lisis agar menjadi lebih detail:

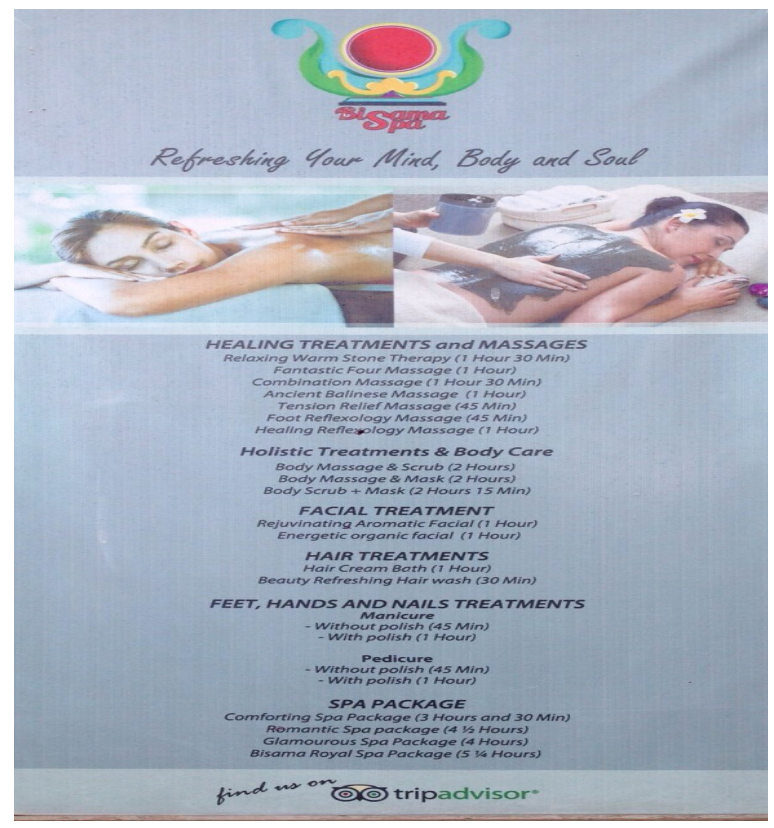


RETORIKA: Jurnal Ilmu Bahasa, Vol. 3, No.1 April 2017, 23

Tabel 04: Struktur wacana iklan D2

\begin{tabular}{|c|c|c|c|c|c|c|c|c|c|}
\hline \begin{tabular}{c} 
Struktur Mak- \\
\multicolumn{7}{|c|}{ Superstruktur } \\
ro
\end{tabular} & \multicolumn{9}{|c|}{ Struktur Mikro } \\
\hline Tematik & $\ddot{O}$ & Skematik & H & I & BC & SL & SD & Semantik & Ö \\
\hline & & O & Ö & O & O & O & Sintaksis & O \\
\cline { 2 - 10 } & & & & & & & Stilisik & \\
\cline { 2 - 10 } & & & & & & & Retoris & Oे \\
\hline
\end{tabular}

Keterangan: $\mathrm{H}=$ Headline

$\mathrm{I}=$ Illustration

$\mathrm{BC}=$ Bodycopy

$\mathrm{SL}=$ Signature Line

$\mathrm{SD}=$ Standing Detail

Deskripsi Tanda pada unsur nonverbal:

Tabel 05: Tanda iklan D2

\begin{tabular}{|c|c|}
\hline Ikon & $\ddot{O}$ \\
\hline Indeks & $\ddot{O}$ \\
\hline Simbol & $\ddot{O}$ \\
\hline
\end{tabular}

Data iklan yang ketiga (D3) adalah iklan banner yang diletakan dipinggir jalan seyang terbitkan oleh perusahaan Nine Heav- bagai strategi promosi agar iklan bisa en Spa. Rumah spa ini terletak disekitar dilihat oleh lebih banyak orang. Berikut jalan Monkey forest ubud yang merupakan tampilan hasil analisis pada iklan Nine pusat keramaian dan wisata dikawasan Heaven Spa dengan metode formal dalam Ubud. Iklan yang diterbitkan oleh Nine bentuk diagram dan tabel untuk menunjang Heaven spa dipublikasikan dalam bentuk hasil analisis agar menjadi lebih detail:

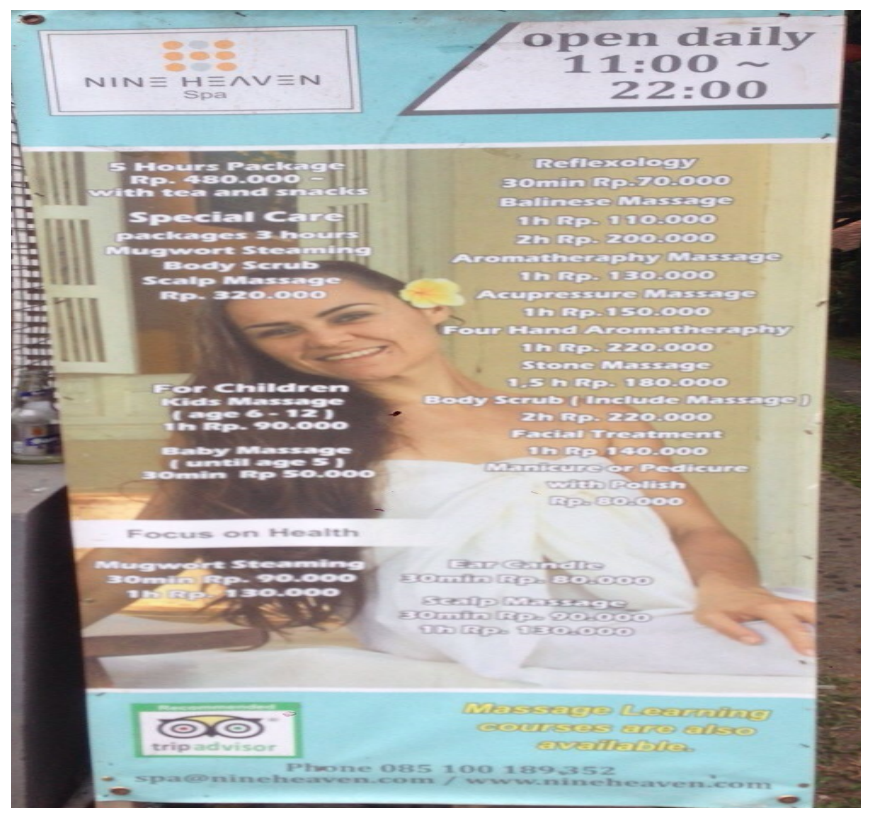


Tabel 06: Struktur wacana iklan D3

\begin{tabular}{|c|c|c|c|c|c|c|c|c|c|}
\hline \multicolumn{2}{|c|}{ Struktur Makro } & \multicolumn{6}{|c|}{ Superstruktur } & \multicolumn{2}{|c|}{ Struktur Mikro } \\
\hline Tematik & $\ddot{O}$ & Skematik & $\mathrm{H}$ & I & $\mathrm{BC}$ & SL & SD & Semantik & $\ddot{\mathrm{O}}$ \\
\hline & & & Ö & Ö & Ö & Ö & Ö & Sintaksis & Ö \\
\hline & & & & & & & & Stilisik & \\
\hline & & & & & & & & Retoris & Ö \\
\hline
\end{tabular}

Keterangan: $\mathrm{H}=$ Headline

$$
\begin{aligned}
& \mathrm{I}=\text { Illustration } \\
& \mathrm{BC}=\text { Bodycopy } \\
& \mathrm{SL}=\text { Signature Line } \\
& \mathrm{SD}=\text { Standing Detail }
\end{aligned}
$$

Deskripsi Tanda pada unsur nonverbal:

Tabel 07: Tanda iklan D3

\begin{tabular}{|c|c|}
\hline Ikon & $\ddot{O}$ \\
\hline Indeks & \\
\hline Simbol & $\ddot{O}$ \\
\hline
\end{tabular}

Data iklan yang keempat (D4) adalah pan iklan (box) yang diletakan dipinggir iklan yang diterbitkan oleh perusahaan Ve- jalan sebagai strategi promosi agar iklan rona Spa. Rumah spa ini terletak disekitar bisa dilihat oleh lebih banyak orang. Berijalan Monkey forest ubud yang merupakan kut tampilan hasil analisis pada iklan Veropusat keramaian dan wisata dikawasan na Spa dengan metode formal dalam bentuk Ubud. Iklan yang diterbitkan oleh Nine Ve- diagram dan tabel untuk menunjang hasil

\begin{tabular}{|c|c|c|c|c|c|c|c|c|c|}
\hline \multicolumn{2}{|c|}{ Struktur Makro } & \multicolumn{6}{|c|}{ Superstruktur } & \multicolumn{2}{|c|}{ Struktur Mikro } \\
\hline Tematik & $\overline{\mathrm{O}}$ & Skematik & $\mathrm{H}$ & $\mathrm{I}$ & $\mathrm{BC}$ & $\overline{\mathrm{SL}}$ & SD & $\begin{array}{c}\text { Semantik } \\
\text { sen }\end{array}$ & $\overline{\mathrm{O}}$ \\
\hline & & & $\ddot{\mathrm{O}}$ & $\ddot{\mathrm{O}}$ & $\overline{\mathrm{O}}$ & $\ddot{\mathrm{O}}$ & $\overline{\mathrm{O}}$ & Sintaksis & $\overline{\mathrm{O}}$ \\
\hline & & & & & & & & $\begin{array}{l}\text { Stilisik } \\
\end{array}$ & \\
\hline & & & & & & & & Retoris & \\
\hline
\end{tabular}
rona spa dipublikasikan dalam bentuk pa- analisis agar menjadi lebih detail:

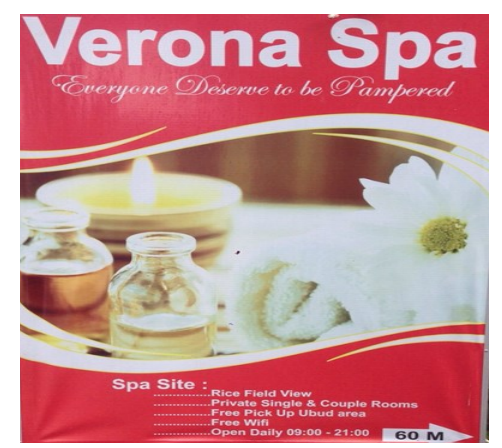

Tabel 08: Struktur wacana iklan D4 
Keterangan: $\mathrm{H}=$ Headline

$$
\begin{aligned}
& \mathrm{I}=\text { Illustration } \\
& \mathrm{BC}=\text { Bodycopy } \\
& \mathrm{SL}=\text { Signature Line } \\
& \mathrm{SD}=\text { Standing Detail }
\end{aligned}
$$

Deskripsi Tanda pada unsur nonverbal:

Tabel 09: Tanda iklan D4

\begin{tabular}{|c|c|}
\hline Ikon & Ö \\
\hline Indeks & \\
\hline Simbol & \\
\hline
\end{tabular}

Data iklan yang kelima (D5) adalah contoh iklan yang diterbitkan oleh perusahaan Shambala Spa. Rumah spa ini terletak di jalan Monkey forest yang merupakan pusat keramaian wisata di Ubud. Iklan yang diterbitkan oleh perusahaan shambala spa diterbitkan dalam bentuk neon box yang pajang dipinggir jalan agar mudah dilihat oleh khalayak ramai. Berikut tampilan hasil analisis pada iklan Shambala Spa dengan metode formal dalam bentuk diagram dan tabel untuk menunjang hasil analisis agar

\begin{tabular}{|c|c|c|c|c|c|c|c|c|c|}
\hline \multicolumn{2}{|c|}{ Struktur Makro } & \multicolumn{6}{|c|}{ Superstruktur } & \multicolumn{2}{|c|}{ Struktur Mikro } \\
\hline Tematik & $\overline{\mathrm{O}}$ & Skematik & $\mathrm{H}$ & I & $\overline{\mathrm{BC}}$ & SL & SD & Semantik & $\overline{\mathrm{O}}$ \\
\hline & & & Ö & $\overline{\mathrm{O}}$ & $\ddot{\mathrm{O}}$ & $\ddot{\mathrm{O}}$ & $\ddot{\mathrm{O}}$ & Sintaksis & $\ddot{\mathrm{O}}$ \\
\hline & & & & & & & & Stilisik & \\
\hline & & & & & & & & Retoris & \\
\hline
\end{tabular}
menjadi lebih detail:

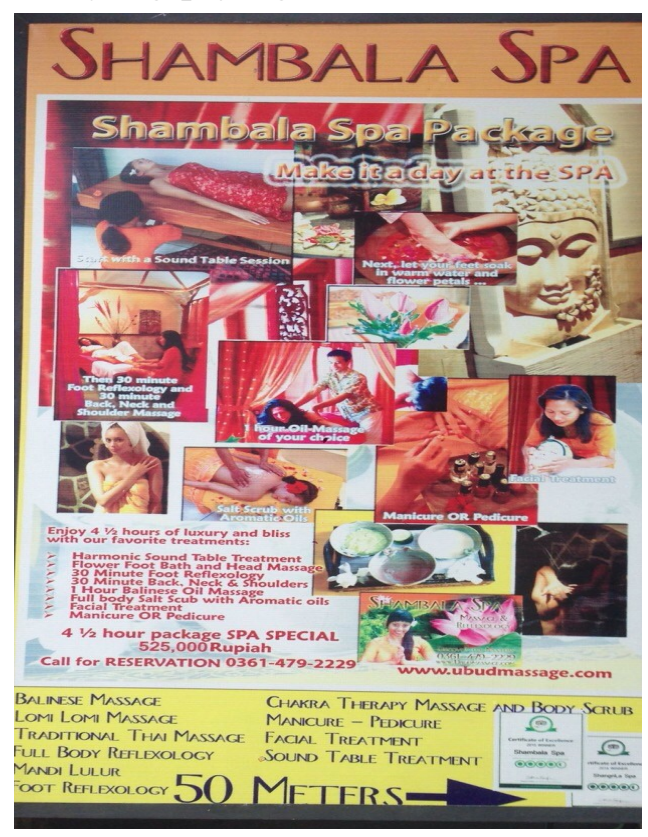

Tabel 10: Struktur wacana iklan D5 


$$
\begin{aligned}
& \text { Keterangan: } \mathrm{H}=\text { Headline } \\
& \mathrm{I}=\text { Illustration } \\
& \mathrm{BC}=\text { Bodycopy } \\
& \mathrm{SL}=\text { Signature Line } \\
& \mathrm{SD}=\text { Standing Detail }
\end{aligned}
$$

Deskripsi Tanda pada unsur nonverbal:

Tabel 11: Tanda iklan D5

\begin{tabular}{|c|c|}
\hline Ikon & Ö \\
\hline Indeks & $\ddot{\mathrm{O}}$ \\
\hline Simbol & \\
\hline
\end{tabular}

Data iklan yang keenam (D6) adalah iklan yang terbitkan oleh perusahaan Taksu Spa and Salon. Rumah spa ini terletak disekitar jalan Hanoman Ubud yang juga merupakan pusat keramaian dan wisata dikawasan Ubud. Iklan yang diterbitkan oleh Taksu spa and Salon dipublikasikan dalam bentuk brosur yang diletakan dipinggir jalan untuk dibagikan ke setiap konsumen yang ingin mengetahui pelayanan dan fasilitas yang terdapat pada rumah spa tersebut, sebagai strategi promosi agar iklan bisa dilihat oleh lebih banyak orang. Iklan yang diterbitkan oleh perusahaan Taksu Spa and Salon menampilkan gaya yang berbeda, selain menampilkan harga dan fasilitas terhadap produk spa, Taksu Spa and Salon juga menawarkan fasilitas terhadap produk salon yang dipaket kedalam jenis fasilitas yang berbeda. Berikut tampilan hasil analisis pada iklan Taksu Spa dan Salon dengan metode formal dalam bentuk diagram dan tabel untuk menunjang hasil analisis agar menjadi lebih detail:

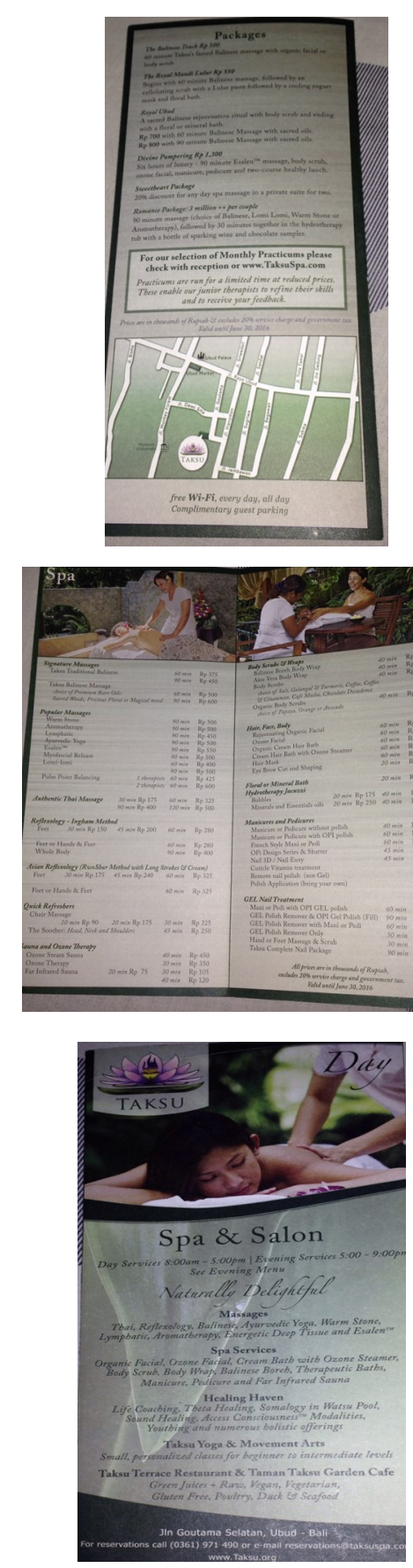


Tabel 12: Struktur wacana iklan D6

\begin{tabular}{|c|c|c|c|c|c|c|c|c|c|}
\hline \multicolumn{2}{|c|}{ Struktur Makro } & \multicolumn{6}{|c|}{ Superstruktur } & \multicolumn{2}{|c|}{ Struktur Mikro } \\
\hline Tematik & $\overline{\mathrm{O}}$ & Skematik & $\overline{\mathrm{H}}$ & I & $\mathrm{BC}$ & $\overline{\mathrm{SL}}$ & SD & Semantik & $\bar{O}$ \\
\hline & & & $\overline{\mathrm{O}}$ & $\overline{\mathrm{O}}$ & $\tilde{\mathrm{O}}$ & $\tilde{O}$ & $\ddot{\mathrm{O}}$ & Sintaksis & $\ddot{\mathrm{O}}$ \\
\hline & & & & & & & & $\begin{array}{l}\text { Stilisik } \\
\end{array}$ & \\
\hline & & & & & & & & Retoris & \\
\hline
\end{tabular}

Keterangan : $\mathrm{H}=$ Headline

$\mathrm{I}=$ Illustration

$\mathrm{BC}=$ Bodycopy

$\mathrm{SL}=$ Signature Line

$\mathrm{SD}=$ Standing Detail

Deskripsi Tanda pada unsur nonverbal:

Tabel 13: Tanda iklan D6

\begin{tabular}{|c|c|}
\hline Ikon & Ö \\
\hline Indeks & O \\
\hline Simbol & $\ddot{O}$ \\
\hline
\end{tabular}

\section{SIMPULAN}

Berdasarkan keseluruhan uraian analisis penelitian, dapat diatarik tiga poin sebagai simpulan penelitian sesuai dengan rumusan permasalahan penelitian. Berikut merupakan ketiga kesimpulan tersebut:

Enam iklan spa yang dianalisis pada penelitian ini memiliki ketiga struktur wacana seperti yang diungkapkan oleh Van Dijk (2009), yaitu struktur makro, superstruktur dan struktur mikro. Enam iklan rumah spa tersebut memiliki strukur makro yang lengkap, sedangkan pada tatanan superstrukur, ada beberapa iklan yang memiliki superstruktur iklan kurang lengkap. Iklan D1 hanya memiliki tiga dari lima struktur iklan yang ada yaitu headline, bodycopy dan signature line. Iklan D2 memiliki struktur iklan yang lengkap yaitu headline, illustration, bodycopy, signature line dan standing details. Iklan D3 memiliki struktur yang lengkap yaitu headline, illustration, bodycopy, signature line dan standing details. Iklan D4 hanya memiliki empat struktur yaitu headline, illustration, bodycopy dan standing details. Iklan D5 memiliki struktur yang lengkap yaitu headline, illustration, bodycopy, signature line dan standing details dan pada iklan D6 memiliki struktur yang lengkap yaitu yaitu headline, illustration, bodycopy, signature line dan standing details. Dari enam iklan yang dianalis, terdapat empat iklan yang memiliki struktur yang lengkap, satu iklan yang memiliki empat struktur dan satu iklan memiliki tiga struktur. Pada tatanan struktur mikro setiap iklan memiliki unsur semantik dan sintaksis, namun ada beberapa iklan yang memiliki unsur retoris seperti pada contoh iklan D2 dan D3. 
Enam iklan yang dianalisis pada penelitian ini memiliki makna verbal yang dianalisis melalui strukur makro dan mikro yang merupakan bagian struktur wacana pada iklan. Sesuai dengan yang diungkapkan Van Dijk (1998) Struktur makro pada iklan yang merupakan tema atau pokok dari sebuah isi berita yang dikedepankan dalam suatu iklan dan menunjuk pada gambaran umum dari suatu teks, gagasan inti dan yang utama dalam suatu teks, dan struktur mikro pada tatanan semantik dikategorikan sebagai makna lokal yang muncul dari hubungan antar kalimat yang membangun makna tertentu dalam suatu teks. Secara tidak langsung kedua unsur tersebut mengungkap makna pada teks verbal pada setiap iklan yang dianalisis pada penelitian ini.

Enam iklan yang dianalisis pada penelitian ini memiliki makna nonverbal yang diungkapkan melalui tanda yang terdapat pada iklan tersebut berupa ikon, indeks dan simbol. Pada penelitian ini, tidak semua iklan memiliki makna verbal seperti yang diungkapkan melalui tanda, diantara semua iklan yang dianalisis pada penelitian ini memiliki ikon, namun tidak semua memiliki indeks dan simbol. Pada iklan D1 hanya terdapat ikon dan tidak memiliki indeks dan simbol, pada iklan D2 memiliki tanda yang lengkap yaitu ikon, indeks dan simbol, pada iklan D3 memiliki tanda yang lengkap yaitu ikon, indeks dan simbol, pada tanda D4 hanya memiliki satu tanda yaitu ikon, pada iklan D5 hanya memiliki ikon dan indeks dan yang terakhir pada iklan D6 memiliki tanda yang lengkap yaitu ikon, indeks dan simbol. Dari enam iklan yang dianalisis tiga iklan memiliki tanda nonverbal yang lengkap, dua iklan memiliki dua tanda, dan satu iklan yang memiliki satu tanda.

\section{UCAPAN TERIMAKASIH}

Penulis mengucapkan terima kasih kepada mitra bestari atas kritikan dan masukan yang membangun untuk perbaikan artikel ini.

\section{DAFTAR PUSTAKA}

Alex S. Nitisemito. 1981. Marketing. Jakarta: Ghalia Indonesia.

Budiman, Kris. 1999b. Kosa Semiotika. Yogyakarta: LKIS

Danesi, Marcel. 2011. Pesan, tanda, dan makna. Diterjemahkan oleh: Evi Setyarini dan Lusi Lian Piantari. Yogyakarta: Jalasutra

Darma, Yoce Aliah. 2009. Analisis Wacana Kritis. Bandung : Yrama Widya.

Eriyanto. 2001. Analisis Wacana: Pengantar Analisis Teks Media. Yogyakarta:

Percetakan Lkis

Halliday, M.A.K. dan Ruqaiya Hasan. 1976. Cohession in English. London \& NewYork: Longman

Halliday, M.A.K; Ruqaiya Hasan. (1994). Bahasa Konteks dan Teks: Aspek-aspek Bahasa dalam Pandangan Semiotik Sosial. (Terjemahan Asruddin Barori Tou). Yogyakarta: UGM Press.

Karang. Grahayani. 2015. Iklan Hotel berbahasa Jepang: Kajian Semiotik. Kumpulan Tesis Program Pascasarjana Universitas Udayana.

KBBI (kamus Besar Bahasa Indonesia). 1998, Jakarta: Balai Pustaka

Kotler, Philip dan Amstrong Gerry. 1997. Dasar - dasar Pemasaran Jilid 2. Jakarta: Prenhallindo.

Leech, Geoffrey N. 1996. English in Advertising: A Linguistic study of Advertising in great Britain. London and New york: Longman

Mahayani. Ni Putu Sri. 2011. Teks iklan layanan masyarakat: Kajian semiotik Kumpulan Tesis Program Pascasarjana 
Universitas Udayana.

Moleong. J. Dr Lexy. 2010. Metodologi Penelitian Kualitatif edisi Revisi. Rosdakarya. Bandung

Mulyawan. I Wayan. 2005. Wacana Iklan Komersial Media Cetak: Kajian Hipersemiotika Kumpulan Tesis Program Pascasarjana Universitas Udayana.

Philip, Bonnie.D. 1983. Business Communication. Canada : Delman Publisher, Inc.

Pratiwi, Desak Putu Eka. 2015. Iklan Komersial Pada Media Elektronik: Gaya Bahasa, Makna, dan Ideologi. Kumpulan Tesis Program Pascasarjana Universitas Udayana.

Quirk, Randolph. et.al. 1972. A Grammar Of Contemporary. English. London : Longman Group Limited.
Ratna, Kutha Nyoman. 2010. Metodologi penelitian: Kajian Budaya dan Ilmu Sosial pada umumnya. Yogyakarta: Pustaka Pelajar.

Short ,T. L. 2007 Peirce's Theory of Signs. New York: Cambridge University Press.

Sobur. Alex. 2001. Analisis Teks Media. Rosdakarya. Bandung

Sobur. Alex. 2009. Semiotika Komunikasi. Rosdakarya. Bandung

Sugiyono. 2014. Metode Penelitian Kombinasi (Mixed Methods). Alfabeta. Bandung

Syamsuddin. A.R. 1992. Studi Wacana: Teori Analisis Pengajaran. Bandung: Mimbar Pendidikan Bahasa Dan Seni.

Van Dijk, Teun. 2009. Society and Discourse; How Social Contexts Influence Text and Talk. Cambridge University Press. 